\title{
POLÍTICA DE EMPREGABILIDADE NO GOVERNO LULA: REFLEXÕES SOBRE O PROGRAMA NACIONAL DE ESTÍMULO AO PRIMEIRO EMPREGO PARA OS JOVENS ${ }^{1}$
}

Maria Aparecida Milanez Cavalcante - Universidade Federal do Piauí ${ }^{2}$

\section{RESUMO}

As reflexões apresentadas referem-se à política de empregabilidade adotada no primeiro governo Lula (2003-2006) com a finalidade de responder à problemática social da juventude e do desemprego com vistas à geração de emprego e renda. Para tanto, analisa-se o Programa Nacional de Estímulo ao Primeiro Emprego para os Jovens - PNPE (2003-2008), dando ênfase à concepção política, diretrizes, público-alvo e orçamento. Com estes parâmetros busca-se uma aproximação sobre as características da política adotada para o enfrentamento do desemprego entre jovens e sua relação com o modelo de política econômica e social neodesenvolvimentista deste período.

Palavras-Chave: Juventudes. Governo Lula (2003-2006). Políticas de Empregabilidade. Programa Nacional de Estímulo ao Primeiro Emprego para os jovens.

\section{ABSTRACT}

The reflections presented refer to the employability policy adopted in the first Lula government (2003-2006) for the purpose to respond to the social problems of youth and unemployment with a view to generation employment and income. Therefore, analyze the National Program of First Employment Stimulation for Young People - PNPE (2003-2008), emphasizing the political conception, guidelines, target audience and budget. With these search one approximation of the characteristics of the policy adopted to face youth unemployment and its relationship with the neo-developmental economic and social policy model of this period.

Keywords: Youths. Lula Government (2003-2006). Employability Policies. National. Program of First Employment Stimulation for Young People.

\section{INTRODUÇÃO}

No âmbito da sociologia diversos parâmetros têm sido utilizados para definir a categoria juventude ou juventudes, especialmente nas sociedades modernas de economia capitalista, e regimentados por diferentes paradigmas de pensamento. Essa

\footnotetext{
1 Trabalho apresentado no Congresso Brasileiro Ciência e Sociedade (CBCS 2019), promovido pelo Centro Universitário Santo Agostinho, de 03 a 05 de outubro de 2019, em Teresina-PI.

${ }^{2}$ Mestre em Sociologia pela UFPI. Doutoranda no Programa de Pós-Graduação em Políticas Públicas da Universidade Federal do Piauí. E-mail: cida_milanez@ hotmail.com.
} 


\section{CONGERSSO CIENCIAESOCIEDADE

categoria tem sido gestada desde concepções que separam a juventude da vida adulta e em interpelação geracional, em que "os jovens interiorizaria e reproduziriam na sua vivência cotidiana uma série de crenças, normas, valores e símbolos próprios das gerações adultas" (PAIS, 1993, p. 42) até o entendimento de que as juventudes passam a ser vistas como sujeitos potenciais ao mercado e à proletarização, criando um modo de ser jovem ancorado nas relações de trabalho, inclusive de desenvolvimento sexual do trabalho, o que deu vigor às correntes classistas (PAIS, 1993, p. 44).

É preciso diferenciar as situações juvenis, ou seja, como a condição juvenil é vivida, na perspectiva de classe social, do gênero, da raça, da etnia, do território, dentre outros, fragmentando a ideia dominante do conceito de juventude e constituindo, assim, "juventudes, no plural, e não juventude, no singular, para não esquecer as diferenças e desigualdades que atravessam essa condição" (ABRAMO, 2005, p. 43-44).

Empiricamente a problemática social da juventude, delimitada para os limites deste trabalho, é o desemprego no contexto da crise capitalista mundial e, especificamente seus rebatimentos no capitalismo dependente, que afeta os grupos de jovens com a ampliação de vulnerabilidades sociais, entre elas a baixa renda per capita familiar e a baixa escolaridade.

Os segmentos juvenis têm sido impactados pelas crises cíclicas do capital, expressas no crescimento da taxa exponencial do desemprego, que segundo relatório "Tendências Globais de Emprego para a Juventude 2017" da Organização Internacional do Trabalho (OIT), neste ano o desemprego juvenil somou 70,9 milhões de jovens desempregados no mundo. No Brasil, segundo o IBGE (2017) em 2017, das 48,5 milhões de pessoas com 15 a 29 anos de idade, 23,0\% (11,2 milhões) não trabalhavam nem estudavam ou se qualificavam, contra $21,9 \%$ em 2016 . De um ano para o outro, esse contingente cresceu 5,9\%, o que equivale a mais 619 mil pessoas nessa condição.

Observa-se que uma das tensões sofrida pelos segmentos juvenis, das classes populares, é a entrada no mercado de trabalho, sendo os projetos educacionais formais postergados para o futuro, ou mesmo, inconclusos. Com baixa qualificação profissional essa juventude não é incorporada pelo mercado competitivo, ou quando 


\section{congęSSOC CIENCIAESOCIEDADE

ocorre inserção, geralmente são em empregos parciais, temporários, informais, precarizados e aviltantes. Essa tensão é resultante dos processos de reestruturação produtiva do capital, em que os modelos de produção exigem maior flexibilização na organização do trabalho - maior nível de técnica e especialização - e redução dos direitos trabalhistas.

Sobre as representações e modelos instituídos de políticas públicas recentes destinadas aos jovens no Brasil, têm sido construídas por uma interconexão entre aquilo que tende a se tornar uma representação normativa corrente da idade e dos jovens na sociedade e o próprio impacto das ações políticas. A conformação das ações e programas públicos não sofrem apenas os efeitos de concepções, mas podem, ao contrário, provocar modulações nas imagens dominantes que a sociedade constrói sobre seus sujeitos jovens. Assim, "as políticas públicas de juventude não seriam apenas o retrato passivo de formas dominantes de conceber a condição juvenil, mas poderiam agir, ativamente, na produção de novas representações" (SPOSITO e CARRANO, 2003, p 17).

\section{METODOLOGIA}

A discussão que ora é apresentada pauta-se nos estudos sobre políticas de "ativação de mercado" ou políticas de empregabilidade para jovens. Possui abrangência de investigação no âmbito do Programa Nacional de Estímulo ao Primeiro Emprego para os Jovens - PNPE (2003-2008), executado durante o primeiro governo Lula (2003-2006). Para estudo político deste programa alguns eixos foram definidos para análise dos documentos que norteiam o desenho das políticas públicas para a juventude: concepção política; público-alvo; diretrizes; orçamento; gestão. Os documentos utilizados para análise foram: Lei 10.748, de 22 de outubro de 2003 (PNPE); Relatório do PPA (2004-2007); dados das despesas nacional do PNPE, disponíveis no orçamento fiscal da Controladoria Geral da União - CGU. A análise do conteúdo destes dados permite uma aproximação sobre as primeiras respostas do Estado e da Sociedade, no período estudado, à problemática social da juventude aqui 


\title{
CONGEFESOCIENCIAESOCIEDADE \\ Inovaçãa, Diversidaade e Sustentahililitaile
}

delimitada. Também permitirá construir encadeamentos às políticas sucessórias do PNPE durante os demais ciclos governamentais.

\section{O NEODESENVOLVIMENTISMO DO GOVERNO LULA (2003-2006) E AS TENDÊNCIAS DE POLÍTICAS DE EMPREGABILIDADE PARA JOVENS}

Nos limites deste texto não será empreendido uma debate sobre as diferentes compreensões sobre a política econômica e social adotada no primeiro governo Lula, mas busca-se uma aproximação com a interpretação sobre a "era Lula" em que a situa como a inauguração de uma "política neodensenvolvimentista" (BOITO Jr., 2018). Essa nova política resultada do compromisso de classes é sustentada pela base "desenvolvimentista" - "programa de política econômica e social que busca o crescimento econômico do capitalismo brasileiro com alguma transferência de renda, embora o faça sem romper com os limites dados pelo modelo econômico, liberal ainda vigente no país" (BOITO Jr., 2018, p. 105).

O prefixo "neo" para Boito Jr. (2018, p. 106) refere-se que o "neodesenvolvimentismo é o desenvolvimentismo da época do capitalismo neoliberal". E quais seriam as características desse novo modelo econômico e social que caracterizou a "era Lula" e que se diferencia do velho desenvolvimentismo? Boito Jr. (2018, p. 106) assim caracteriza a política neodensenvolvimentista:

\begin{abstract}
a) apresenta um crescimento econômico que, embora seja muito maior que aquele verificado na década de 1990, é bem mais modesto que o propiciado pelo velho desenvolvimentismo; b) confere importância menor ao mercado interno, posto que mantém a abertura comercial herdada de Collor e de FHC; c) atribui importância menor à política de desenvolvimento do parque industrial local; d) aceita os constrangimentos da divisão internacional do trabalho, promovendo condições históricas novas, uma reativação da função primário-exportadora do capitalismo brasileiro; e) tem menor capacidade distributiva da renda; f) o novo desenvolvimentismo é dirigido por uma fração burguesa que perdeu toda veleidade de agir como força social nacionalista e anti-imperialista.
\end{abstract}

A partir da teoria sobre o "bloco no poder" Boito Jr. (2018) analisa as classes sociais e as frações de classes que dirigiram a economia e a política na "era Lula", 


\section{CONGBESSO CIENCGIAESOCIEDADE \\ Inovação, Diversidaale e Sustentahilitilade}

aquela que detém a hegemonia política no interior do bloco no poder - "grande burguesia interna, distribuída em diversos setores da economia - mineração, construção pesada, a cúspide do agronegócio, a indústria de transformação, em certa medida, os grandes bancos privados e estatais de capital predominantemente nacional" (BOITO Jr., 2018, p.108).

No interior do compromisso de classes (POULANTZAS, 1977) as classes dominadas assumem a função de influenciar a política econômica pela força política e pressão social que exercem ao Estado. Para Boito Jr. (2018, p. 109), no campo das classes dominadas da "era Lula", "o operariado urbano e a baixa classe média, por intermédio do Partido dos Trabalhadores, têm uma participação organizada na frente neodesenvolvimentista". Além deste, fazem parte desta frente o campesinato organizado pela luta da terra, a exemplo do Movimento dos Trabalhadores Sem-Terra - MST - têm atendido pela política "neodesenvolvimentista" ampliação de subsídios para a agricultura familiar e estímulo da produção e da compra de produtos via programas como o da merenda escolar e compra direta da agricultura familiar.

Outra frente de base de apoio ao "neodesenvolvimentismo" destaca-se: os desempregados, os movimentos por moradia - uma "massa marginal" (BOITO Jr., 2018) social e politicamente desorganizada. Os governos da "era Lula" mantiveram durante todos os processos de crise política essa base de apoio (base eleitoral), garantida pela troca de política populista, consubstanciada pelo sufrágio universal, que não possuindo organização política, garantiram, por meio do voto, apoio aos governos. Mantiveram essa base de apoio via programas de transferência de renda e um “mínimo de cidadania”.

Entre as estratégias que compõem a política neodesenvolvimentista do governo Lula (2003-2006), por ajustar interesses dominantes do mercado industrial e financeiro, com política de um "mínimo de cidadania" - transferência de renda para os mais pobres, caracterizada como políticas de focalização na pobreza - são as políticas de empregabilidade e empreendedorismo, pois há uma intervenção do Estado na economia capitalista, com política creditícia, de subvenção econômica para o mercado, e como promessa de geração de emprego e renda. Ademais as políticas de 


\section{conghESSO CIENCIAESOCIEDADE

empregabilidade caracterizam-se como estratégia de socialização da crise estrutural do capitalismo contemporâneo, sendo o desemprego uma das expressões que impacta a população em seus diferentes níveis de ciclos produtivos e reprodutivos (jovens e idosos).

As políticas públicas de empregabilidade e empreendedorismo são paulatinamente substituídas por políticas de autoresponsabilização dos desempregados, "redução de custos de formação da força de trabalho e constrangimento da luta sindical, além da criação de lucrativos negócios e da possibilidade real de reduzir o risco de investimentos em novos empreendimentos" (MARTINS, 2014, p.229-230).

Frações da classe trabalhadora que estão desempregados e em trabalhos precários tem sido alvo de um conjunto de políticas chamadas de "ativação" para o mercado de trabalhado, que operam combinadas ou isoladamente, nos países centrais e dependentes.

Trata-se de cursos de qualificação profissional, projetos de geração de emprego e renda, economia solidária, estímulos ao empreendedorismo e ao crédito, programas de transferência de renda, criação do primeiro emprego, estímulo à criação de emprego de jovens, subvenções a empregos (TEIXEIRA, NEVES, 2018, p. 134, grifo meu).

Segundo Martins (2014, p. 259) a empregabilidade apresenta-se como uma teoria de como os trabalhadores podem vencer os outros na disputa por empregos, desconsiderando que um desempregado vencer outros desempregados não combate o desemprego, mas tão somente, ensina como não ser um desempregado em meio a tantos outros. Ademais a empregabilidade, também, promove a mercantilização da oferta de empregos, mesmo se referindo a políticas públicas.

A empregabilidade remete ao entendimento da "capacidade de um obter emprego" ou a "aptidão dos trabalhadores em conquistar um emprego e mantê-lo todos os dias prosperando numa sociedade sem empregos" (MARTINS, 2014, p. 23231). 


\section{congęSSOC CIENCIAESOCIEDADE

É importante destacar, para melhor qualificar a definição acima, o seu sentido dentro da política social. Para Behring (2011), a política social possui uma relação com as opções políticas, econômicas e sociais de cada governo, e que a capacidade de cobertura de um padrão de proteção social é diretamente proporcional à condição de posição econômica mundial (capitalismo central ou periférico). Para a autora em ambos, ocorre uma disputa em torno do aumento ou diminuição das despesas públicas, por parte do capital e do trabalho.

Em termos de modelo de proteção social vivenciado pelos países de capitalismo avançado infere-se que ocorreu após a crise do modelo fordista/keynesiano o deslocamento do modelo de welfare para o modelo workfare. Portanto, as tendências de políticas de "ativação" para o mercado de trabalho estão implicadas na lógica de reprodução do sistema capitalista, em seu estágio avançado, e que se tornam diretrizes para políticas governamentais de países de capitalismo dependente, sob orientação de organismos gestores dos processos de crise, a exemplo da Organização Internacional do Trabalho (OIT).

As medidas de "ativação" para mercado de trabalho estão dispostas na Declaração Socio-Laboral do Mercosul ${ }^{3}$, com destaque para o "fomento do emprego" (art. 14) e "formação profissional e de recursos humanos" (art. 16). São políticas que visam a focalização de grupos (mais pobres e pouco qualificados) em situação de desvantagem no mercado de trabalho.

\section{AS CARACTERISTICAS POLÍTICAS DO PROGRAMA NACIONAL DE ESTÍMULO AO PRIMEIRO EMPREGO PARA OS JOVENS}

Para apresentação dos resultados da análise crítica da política referente à ideologia da empregabilidade presente no conteúdo do Programa Nacional de Estímulo ao Primeiro Emprego para os Jovens - PNPE, o texto seguirá as seguintes seções: concepção política, público-alvo, diretrizes e orçamento.

\footnotetext{
${ }^{3}$ A Declaração Sociolaboral do MERCOSUL foi pactuada em 1998 entre os países membros. Em 2015 a esta declaração é reformulada e reafirmada entre seus países membros. Nas duas edições aparece a dimensão do fomento ao emprego e da formação profissional.
} 


\section{CONGEFESOCIENCIAESOCIEDADE

O PNPE consiste em estratégia governamental no início do primeiro governo Lula (2003-2006) articulado pelo Ministério da Fazenda ${ }^{4}$, Ministério do Estado do Trabalho e Emprego ${ }^{5}$, e do Ministério do Estado do Orçamento e da Gestão ${ }^{6}$, em orientação à Presidência da República para a proposição ao congresso nacional. Ou seja, observa-se que a proposta do programa parte do próprio executivo, fazendo parte de seu programa de governo. Como justificativa tem-se a elevada taxa de desemprego entre a população jovem no período. Por outro lado, destaca-se também, que tais políticas estejam associadas à política econômica adotada de estímulo ao capital industrial nacional para a criação de novos postos de emprego via subvenção econômica à geração de empregos destinados a jovens.

Uma série de medidas é tomada no primeiro governo Lula (2003-2006) como estratégias de ampliação do mercado de trabalho para jovens, em resposta a ampliação da taxa de desemprego resultante da crise estrutural do capitalismo. As políticas de formação, de geração de emprego e renda e "ativação" do mercado de trabalho, expressas no Plano Plurianual (2004-2007) não se afastam de concepções políticas que buscam alinhar desenvolvimento econômico e social com alianças entre o Estado e o capital (industrial e financeiro), e legitimação frente a sociedade civil organizada. Costuram parcerias com empresas capitalistas via subvenção econômica para a criação de vagas de emprego para jovens; estímulo ao trabalho voluntário, e a geração de inputs para o empreendedorismo articulada a política creditícia, que muitas vezes, acabam endividando os beneficiários tendo em vista serem suplantados pelo mercado globalizado.

A partir da análise política do PNPE (Lei 10.748, de 22 de outubro de 2003), destaca-se:

a) Concepção política: o PNPE é um programa inscrito dentro das orientações para políticas de ativação de mercado e geração de emprego e renda para jovens como resposta a alta taxa de desemprego neste grupo social. Objetiva

\footnotetext{
${ }_{5}^{4}$ Ministro Antônio Palocci Filho.

5 Ministro Jaques Wagner.

${ }^{6}$ Ministro Guido Mantega.
} 


\section{CONGEFESOCIENCIAESOCIEDADE

tanto a inserção no mercado quanto a ampliação da escolaridade de jovens via sistema de condicionalidades. Também busca a participação da sociedade no processo de formulação de políticas e ações de geração de emprego e renda, articulada ao mercado e ao voluntariado.

b) Público-alvo: o programa é focalizado para jovens (16 a 24 anos), em situação de desemprego involuntário, que não tiveram vínculo empregatício anterior, e que sejam integrantes de famílias com renda mensal per capita de até meio salário mínimo. Além disso, o programa prever condicionalidade, uma vez que exige aos beneficiários estarem matriculados e frequentando regularmente estabelecimento de ensino fundamental ou médio, ou cursos de educação de jovens e adultos. Isso implica pensar que a contrapartida por um lago condiciona o acesso ao direito e à reprodução social da juventude, e por outro lado, busca integrar e ampliar o acesso aos direitos sociais ao constituir estímulos a continuidade e permanência das etapas de formação educacional formal.

c) Diretrizes: como diretriz o programa determina que haja proximidade entre residência do jovem e posto de emprego oferecido. O PNPE não abrange trabalho doméstico, nem contrato de experiência. Assim, percebe-se que há certa proteção trabalhista ao jovem e o estímulo ao emprego como natureza formativa e profissionalizante ao não contemplar a inserção de jovens em empregos domésticos. Possui diretriz de orientação à formalidade e permanência no posto de emprego, porém deixa a critério do empregador, caracterizando-se, também, como política de aliança entre Estado e mercado. Observa-se esta tendência no art. 2--A. "Os contratos de trabalho celebrados no âmbito do PNPE poderão ser por tempo indeterminado ou determinado, nos termos da Consolidação das Leis do Trabalho - CLT" (BRASIL, 2003, p.3). Porém, apresenta obrigatoriedade, em caso de contrato por tempo determinado, a definição de no mínimo 12 meses de duração do vínculo (art. 


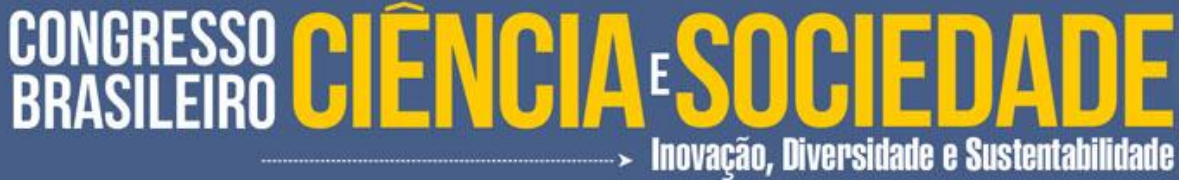

12). O cadastramento de jovens realizado nas unidades de atendimento do Sistema Nacional de Emprego - SINE.

d) Financiamento: o PNPE esteve coordenado, executado e supervisionado pelo Ministério do Trabalho e Emprego e com recursos do Fundo de Amparo ao Trabalhador - FAT. O PNPE prever subvenção econômica aos contratantes de jovens cadastrados no programa, porém a concessão ao ser condicionada pela disponibilidade de recursos financeiros, do Ministério do Trabalho e Emprego, implica em averiguar a progressão ou regressão desse financiamento como parte de políticas direcionadas à empregabilidade de jovens.

TABELA 1: Orçamento do PNPE realizado no PPA (2004-2007).

\begin{tabular}{|l|r|r|r|r|r|}
\hline Dotação dos Orçamentos Fiscais e da Seguridade Social do PPA (2004-2007) \\
\hline Despesa nacional do Programa Nacional de Estímulo ao Primeiro Emprego para Jovens - PNPE por Ano \\
\hline Importância/Ano & $\mathbf{2 0 0 4}$ & \multicolumn{1}{c|}{$\mathbf{2 0 0 5}$} & \multicolumn{1}{c|}{$\mathbf{2 0 0 6}$} & \multicolumn{1}{c|}{$\mathbf{2 0 0 7}$} & PNPE (PPA 2004-2007) \\
\hline Inicial (R\$̧) & $188.200 .000,00$ & $139.730 .456,00$ & $147.818 .860,00$ & $120.417 .000,00$ & $596.166 .316,00$ \\
\hline Suplementação (R\$) & $-28.654 .687,00$ & $-337.553,00$ & $-55.318 .907,12$ & -10.000 .000 & $-94.311 .147,12$ \\
\hline Autorizada (R\$) & $159.545 .313,00$ & $139.392 .903,00$ & $92.499 .952,88$ & $110.417 .000,00$ & $501.855 .168,88$ \\
\hline
\end{tabular}

Fonte: Elaboração própria. Dados de despesas (regionalizada) do Orçamento fiscal. Controladoria Geral da União - CGU. Ano (2004; 2005; 2006; 2007).

A tabela 1 apresenta o orçamento de despesas nacional para o PNPE prevista no Plano Plurianual (2004-2007) mostrando que desde o início o programa desempenhou um montante regressivo de recurso orçamentário. E em todas as séries anuais, o programa apresenta suplementação negativa - indicativo de que parte do orçamento previsto foi direcionada para outras despesas

\section{CONSIDERAÇÕES FINAIS}

A análise política do Programa Nacional de Estímulo ao Primeiro Emprego para os Jovens (PNPE) faz inferir que durante o primeiro governo Lula (2004-2007) a problemática social da juventude é entendida correlata ao problema do desemprego 


\section{CONQEFESSOCIENCIAESOCIEDADE

estrutural, por atingir parcela significativa deste grupo social. A resposta governamental articula política econômica e política social, no intuito de reverter ciclos da crise capitalista via políticas de fortalecimento do setor produtivo com subvenções econômicas à empresa capitalista, e por outro lado, uma política social compensatória e focalizada nos mais pobres para a criação de empregos e renda aos jovens e famílias com baixa renda mensal per capita. Pode-se inferir que tal estratégia insere-se nas políticas ativas de mercado de trabalho, via subvenção econômica ao capital.

Possui uma relação entre Estado, mercado e sociedade civil para a socialização dos processos construtores de desigualdade de oportunidades de acesso e renda. Também, revaloriza o serviços de voluntariado, reeditando práticas de regressão dos direitos sociais trabalhistas, e caracterizando a face heterodoxa do neodesenvolvimentismo, por não romper inteiramente com o neoliberalismo.

Neste sentido o PNPE apresenta continuidades e rupturas com a política neoliberal, a primeira por valorizar o voluntariado e a subvenção econômica ao mercado. E de ruptura, por estimular a própria economia nacional com os estímulos de criação de posto de emprego, revalorizando uma "política keynesiana às avessas" com políticas de estímulo ao emprego, sem enfrentar as estruturas de organização da produção capitalista flexível. Destaca-se do ponto de vista de ampliação dos direitos sociais por buscar enfrentar, com programas de emprego para jovens, a problemática social das juventudes não pensadas em governos anteriores com agenda neoliberal.

\section{REFERÊNCIAS}

ABRAMO, H. W. Condição juvenil no Brasil Contemporâneo. In: ABRAMO, H. W. e BRANCO, P. P. M. (org.) Retratos da juventude brasileira: análises de uma pesquisa nacional. São Paulo: Editora Fundação Perseu Abramo e Instituto da Cidadania, 2005.

BEHRING, E. Política Social no Capitalismo Tardio. 3 ed. São Paulo: Cortez, 2011.

BOITO Jr., A. As bases políticas do neodesenvolvimentismo. In: BOITO Jr., A. Reforma e crise política no Brasil: os conflitos de classe nos governos do PT. Campinas, SP: editora da Unicamp/ São Paulo, SP: Editora da UNESP, 2018. p. 99-120. 


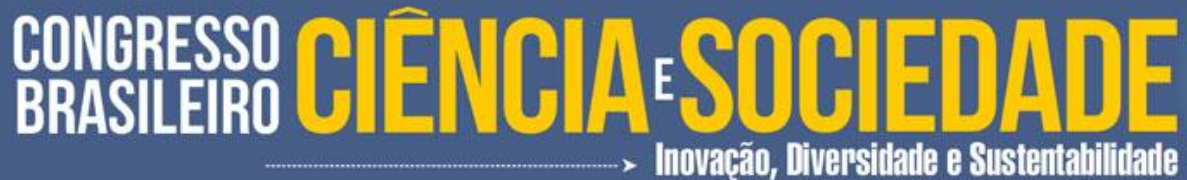

BRASIL. LEI no 10.748, de 22 de outubro de 2003. Cria Programa Nacional de Estímulo ao Primeiro Emprego para os Jovens - PNPE, acrescenta dispositivo à lei 9.608 de fevereiro de 1998, e dá outras providências. Brasília [2003]. Disponível em: http://www.planalto.gov.br/ccivil 03/LEIS/2003/L10.748.htm. Acesso em: 20 de ago. 2019.

Ministério do Planejamento, Orçamento e Gestão. Relatório de Avaliação do Plano Plurianual 2004-2007. Brasília: MP, 2008.

Instituto Brasileiro de Geografia e Estatística (IBGE). Pesquisa sobre o mercado de trabalho. Disponível em: https://agenciadenoticias.ibge.gov.br/agencia-sala-deimprensa/2013-agencia-de-noticias/releases/21253-pnad-continua-2017-numero-dejovens-que-nao-estudam-nem-trabalham-ou-se-qualificam-cresce-5-9-em-um-ano. Acesso em: 01 de out. 2018.

MARTINS, G. Nem empregabilidade, nem Empreendedorismo: crítica às soluções contemporâneas ao desemprego. In: MONTAÑO, C. (org.). O Canto da Sereia: crítica à ideologia e aos projetos do "terceiro setor". São Paulo: Cortez, 2014. p. 228-267.

PAIS, José Machado. Culturas Juvenis. Lisboa: Imprensa Nacional Casa da Moeda, 1993.

POULANTZAS, N. Poder político e classes sociais. Tradução: Francisco Silva; Revisão de Carlos Roberto F. Nogueira. São Paulo: Martins Fontes, 1977.

SPOSITO, Marília Pontes; CARRANO, Paulo César Rodrigues. Juventude e políticas públicas no Brasil. In: Revista Brasileira de Educação, no 24, set/dez de 2003. Disponível em: http://www.scielo.br/pdf/\%0D/rbedu/n24/n24a03.pdf. Acesso em 29 de outubro de 2018.

TEIXEIRA, S. O.; NEVES, D. Trabalho e Assistência Social no capitalismo dependente: uma análise marxista das chamadas políticas "ativas de mercado de trabalho". In: BOSCHETTI, I; BEHRING, E; LIMA R. de L. de. (org.). Marxismo, política social e direitos. São Paulo: Cortez, 2018. p. 133-164. 